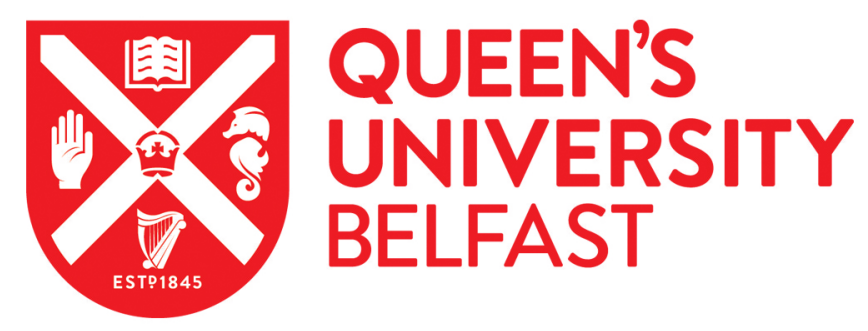

\title{
Solvent-Free, Continuous Synthesis of Hydrazone-Based Active Pharmaceutical Ingredients by Twin-Screw Extrusion
}

\author{
Crawford, D. E., Porcheddu, A., McCalmont, A. S., Delogu, F., James, S. L., \& Colacino, E. (2020). Solvent- \\ Free, Continuous Synthesis of Hydrazone-Based Active Pharmaceutical Ingredients by Twin-Screw Extrusion. \\ ACS Sustainable Chemistry \& Engineering, 8(32), 12230-12238.
}

https://doi.org/10.1021/acssuschemeng.0c03816

Published in:

ACS Sustainable Chemistry \& Engineering

Document Version:

Publisher's PDF, also known as Version of record

Queen's University Belfast - Research Portal:

Link to publication record in Queen's University Belfast Research Portal

Publisher rights

(C) 2020 American Chemical Society

This is an open access Creative Commons Attribution-NonCommercial License (https://creativecommons.org/licenses/by-nc/4.0/), which permits use, distribution and reproduction for non-commercial purposes, provided the author and source are cited

\section{General rights}

Copyright for the publications made accessible via the Queen's University Belfast Research Portal is retained by the author(s) and / or other copyright owners and it is a condition of accessing these publications that users recognise and abide by the legal requirements associated with these rights.

Take down policy

The Research Portal is Queen's institutional repository that provides access to Queen's research output. Every effort has been made to ensure that content in the Research Portal does not infringe any person's rights, or applicable UK laws. If you discover content in the Research Portal that you believe breaches copyright or violates any law, please contact openaccess@qub.ac.uk. 


\section{Solvent-Free, Continuous Synthesis of Hydrazone-Based Active Pharmaceutical Ingredients by Twin-Screw Extrusion}

Deborah E. Crawford,* Andrea Porcheddu, Aaron S. McCalmont, Francesco Delogu, Stuart L. James, and Evelina Colacino*

Cite This: ACS Sustainable Chem. Eng. 2020, 8, 12230-12238

Read Online

\section{ACCESS |}

Wlll Metrics \& More

| 回 Article Recommendations

Supporting Information

ABSTRACT: Twin-screw extrusion (TSE) was used to synthesize hydantoin-based active pharmaceutical ingredients (APIs) such as nitrofurantoin and dantrolene, employing minimal or no solvent. Postsynthetic workup was not required. This work demonstrates that solvent-free synthesis can be conducted in a continuous manner for pharmaceutical products.

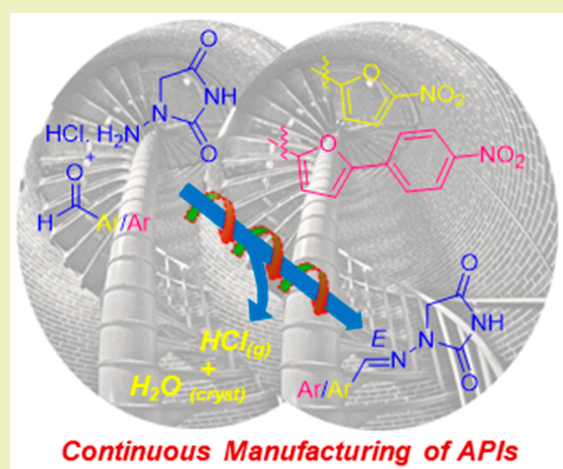

KEYWORDS: Active pharmaceutical ingredients (APIs), Green chemistry, Hydantoins, Hydrazones, Mechanochemistry, Solvent-free, Twin-screw extrusion (TSE)

\section{INTRODUCTION}

Solvents are a key component of chemical manufacture, but they are also a matter of concern since they are typically hazardous, toxic, and add to the cost of production. However, it has been demonstrated, particularly in the last few decades, that many reactions can proceed with the application of mechanical force, typically between solid reactants, in the absence of solvent (i.e., via mechanochemistry). Recently, mechanochemistry has been acknowledged by the International Union of Pure and Applied Chemistry (IUPAC) as one of the "top ten emerging technologies in chemistry" 1 answering to the increasing demand for clean processes and ecoconscious reaction conditions. Indeed, mechanochemistry finds application in organic ${ }^{2,3}$ and organometallic ${ }^{4}$ syntheses, metal ${ }^{5}$ or enzymatic catalysis, ${ }^{6}$ preparation of cocrystals, ${ }^{7}$ metal-organic frameworks $^{8}$ (MOFs) and coordination polymers, ${ }^{9}$ and nano(biohybrid) ${ }^{10-12}$ pharmaceutical ${ }^{13-15}$ materials and ingredients $^{16,17}$ (APIs). A current challenge is therefore to demonstrate the scalability of this solvent-free chemistry toward its application in commercial manufacturing or various product types. Noteworthy is the recent development of new mechanochemical approaches based on twin-screw extrusion (TSE), a technique already employed in the formulation of pharmaceutical products and in food manufacture. It has been successfully employed in the synthesis of organic compounds, ${ }^{18-20} \mathrm{MOFs}^{21,22}$ and peptides, ${ }^{23,24}$ reaching $\mathrm{kg} \mathrm{hr}^{-1}$ scales under solvent-free or minimal-solvent conditions. Furthermore, synthesis can be carried out as a continuous process, and the technology has the potential to be scaled further to ton $\mathrm{hr}^{-1}$ quantities, by scaling to larger industrial extruders. Thus, the use of twin-screw extrusion for the largescale preparation of drug candidates and active pharmaceutical ingredients (APIs) is particularly appealing.

In this work, we focus our attention on two important APIs, namely, dantrolene and nitrofurantoin. Dantrolene (Dantrium) is a prescribed muscle relaxant, used to treat malignant hyperthermia, ${ }^{25}$ while nitrofurantoin (Furantin) is a prescribed antibiotic, used particularly for the treatment of urinary tract infections. ${ }^{26}$

\section{RESULTS AND DISCUSSION}

The solution-based synthesis of these APIs involves a condensation reaction between a furfural derivative and 1aminohydantoin hydrochloride (up to $10 \mathrm{~mol}$. eq ), in a highly concentrated aqueous acid solution, before several heating/ cooling cycles and $\mathrm{pH}$ adjustments are made during workup (Scheme 1). ${ }^{27-30}$ However, this is cumbersome and expensive, requiring (i) the formation of intermediates which require

Received: May 24, 2020

Revised: June 25, 2020

Published: August 5, 2020 
Scheme 1. Industrial Preparation of Hydrazone-Based APIs in Solution

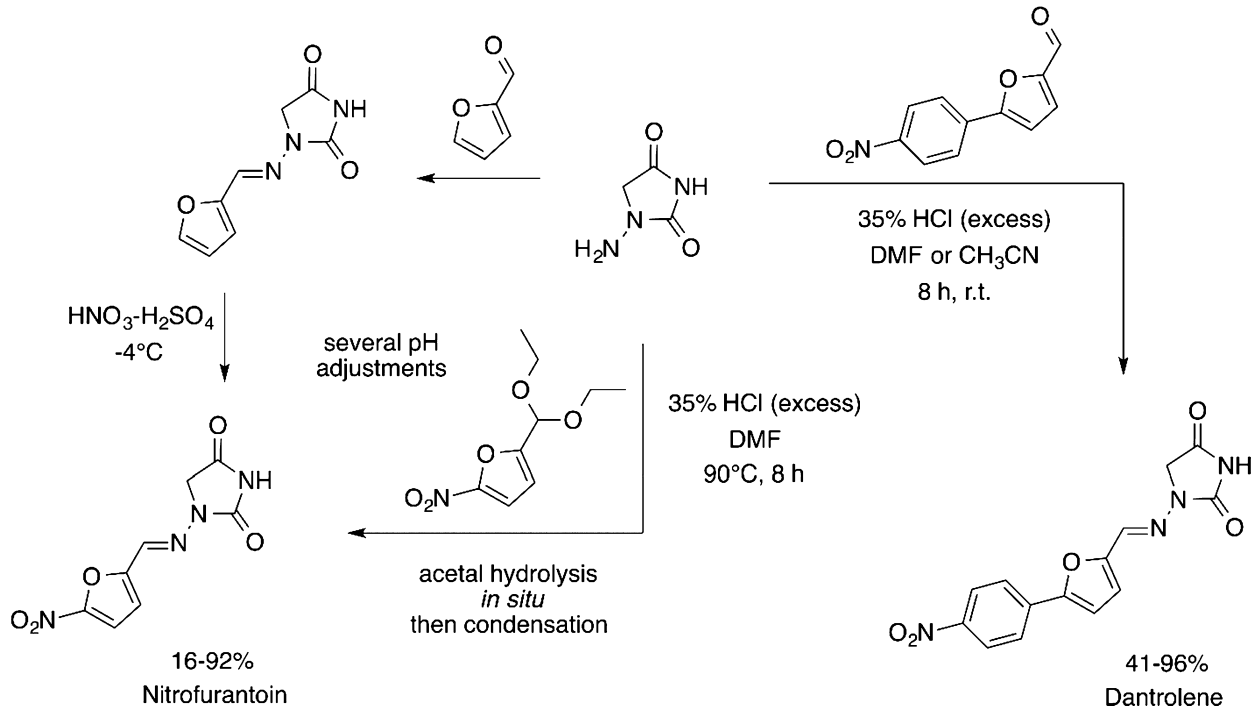

Scheme 2. Model Reactions for TSE of $N$-Acylhydrazones 1 and $2^{a}$
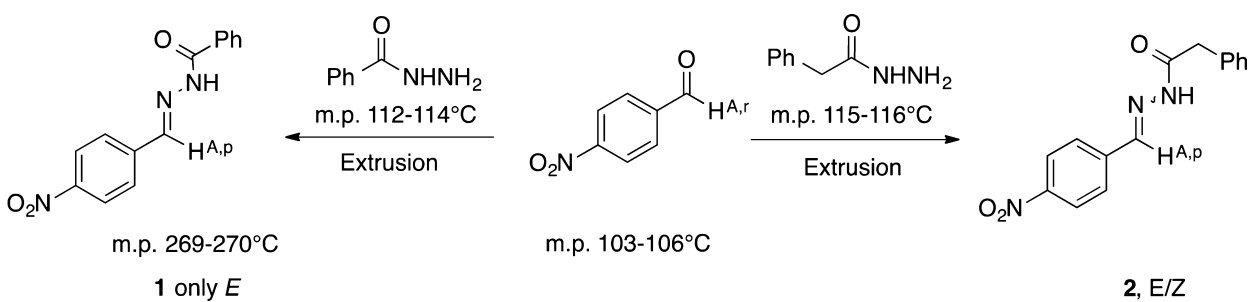

${ }^{a} \mathrm{H}^{\mathrm{A}, \mathrm{r}}$ and $\mathrm{H}^{\mathrm{A}, \mathrm{P}}$ indicate, respectively, the aldehyde proton in the reactant and the $\mathrm{N}$-acylhydrazone proton in the product.

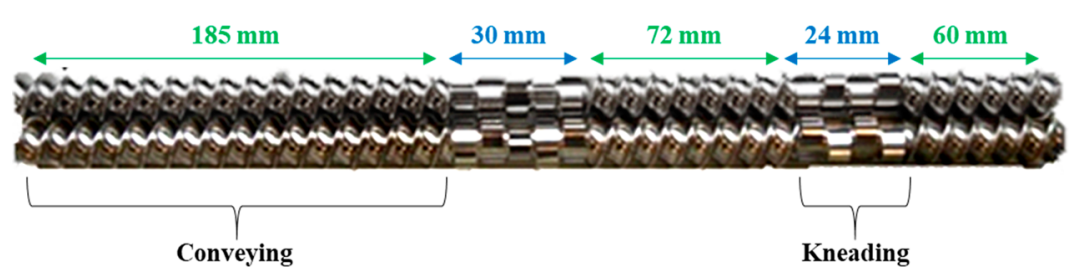

Figure 1. Standard screw configuration employed in the extrusion of compounds $\mathbf{1}$ and $\mathbf{2}$.

purification prior to subsequent use, (ii) large amounts of expensive organic solvents, and (iii) subsidiary recovery cycles for solvents and excess reactants. The impact of these factors on an industrial scale has recently led to significant controversy over the cost of solution synthesis of nitrofurantoin, further emphasizing the need for greener synthetic routes. ${ }^{31}$

Both APIs involves the formation of $\mathrm{N}$-acylhydrazones by reacting an aldehyde with a hydrazide derivative. The $N$ acylhydrazone functionality is of wide interest in medicinal chemistry since it is present in several marketed APIs. We have demonstrated previously that these products can be obtained by employing mechanochemistry, particularly small-scale ball milling, ${ }^{31}$ with a highly improved environmental footprint and at a reduced cost compared to classic solvent-based procedures. ${ }^{32}$ Furthermore, the synthesis in the ball mill was successful without the need for a Brønsted acid (e.g., hydrochloric, $p$-toluenesulfonic or acetic acid) or Lewis acid (e.g., scandium triflate).

The next logical step is to explore scalable synthesis of these APIs under solvent-free conditions. Herein, we present the first examples of $N$-acylhydrazone syntheses employing TSE, followed by the synthesis of nitrofurantoin and dantrolene.

Initially, two model reactions were investigated; the stoichiometric condensations of $p$-nitrobenzaldehyde with (i) benzhydrazide or (ii) phenylacetic hydrazide, leading to $(E)$ $N^{\prime}$-(4-nitrobenzylidene)benzohydrazide 1 and $N^{\prime}$-(4nitrobenzylidene)benzohydrazide 2 , respectively (Scheme 2 ). Use of benzhydrazide and phenylacetic hydrazide allowed investigation of the influence of benzyl/aliphatic versus aryl substituents on the reaction outcome and to optimize conditions accordingly.

Attenuated total reflectance infrared (ATR-IR) spectroscopy was used to monitor the progress of the reactions, in particular, to detect any remaining reagents in the extrudates. ${ }^{1} \mathrm{H}$ NMR spectroscopy was used to quantify the conversions of starting substrates to products and allowed for the $E / Z$-isomer ratio to be confirmed. ${ }^{13} \mathrm{C}$ solid-state NMR spectroscopy enabled the analysis of the products without dissolution in a solvent, eliminating the possibility of the reaction proceeding in the NMR spectroscopy solvent. A screw configuration consisting of two kneading and three conveying sections was employed 


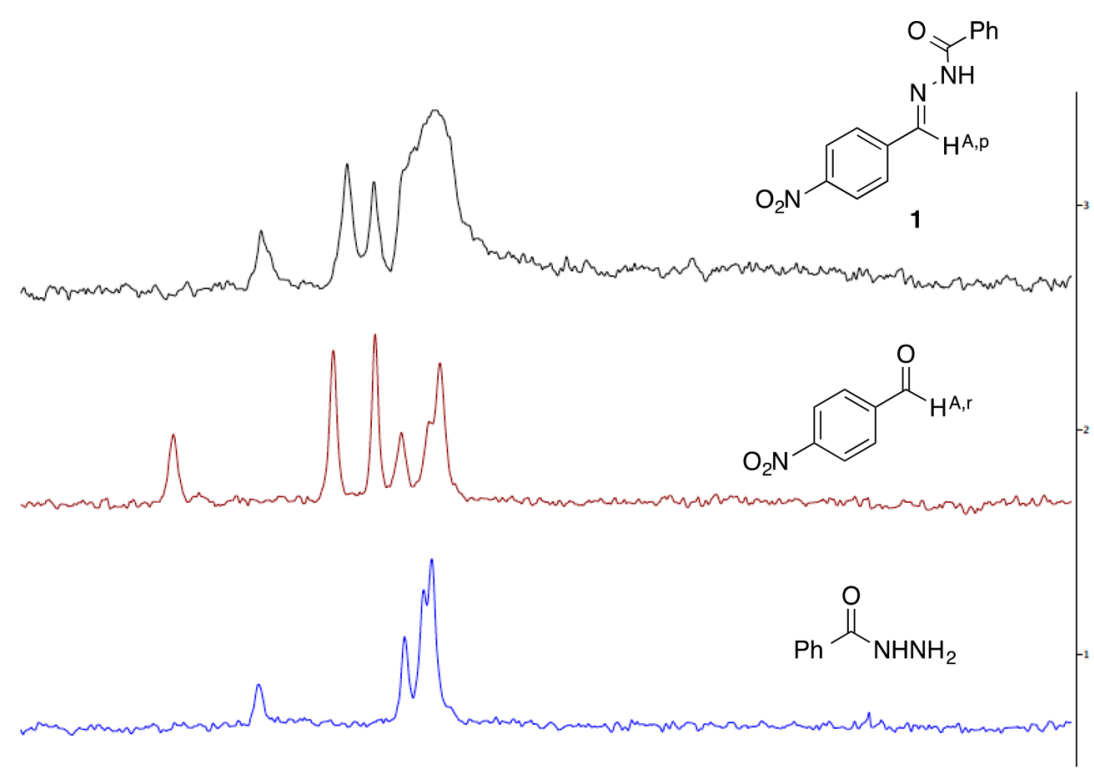

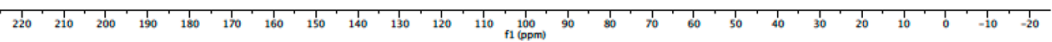

Figure 2. ${ }^{13} \mathrm{C}$ solid-state NMR spectra of reactants benzhydrazide (blue pattern) and $p$-nitrobenzaldehyde (red pattern) vs $\mathrm{N}$-acylhydrazone $\mathbf{1}$ prepared by extrusion (black pattern, Table S1, entry 5). $\mathrm{H}^{\mathrm{A}, \mathrm{r}}$ and $\mathrm{H}^{\mathrm{A}, \mathrm{P}}$ indicate, respectively, the aldehyde proton in the reactant and the $N$ acylhydrazone proton in product $\mathbf{1}$.

(Figure 1), with a residence time of less than $2.0 \mathrm{~min}$. Unlike typical commercially available ball milling devices, the temperature of the extrusion process can be readily controlled. The barrel of the extruder employed comprises six segments that can be heated individually up to $300{ }^{\circ} \mathrm{C}$.

The formation of $\mathbf{1}$ and $\mathbf{2}$ was investigated at barrel temperatures between 20 and $150{ }^{\circ} \mathrm{C}$ and at screw speeds from 55 to $250 \mathrm{rpm}$. The synthesis of 1 was successful at the moderate temperature of $50{ }^{\circ} \mathrm{C}$ and a screw speed of $55 \mathrm{rpm}$ (Table S1), yielding a dark yellow powder. This reaction temperature is significantly lower than the melting points of both benzhydrazide $\left(112-114{ }^{\circ} \mathrm{C}\right)$ and $p$-nitrobenzaldehyde $\left(103-106{ }^{\circ} \mathrm{C}\right)$ reactants, suggesting that a solid-state reaction is occurring, i.e., without the involvement of significant amounts of bulk molten phases. The corresponding spacetime yield (STY), i.e., the amount of product synthesized per unit reactor volume of the extruder per unit time, was $62 \times 10^{3}$ $\mathrm{kg} \mathrm{m}^{-3}$ day $^{-1}$. This is significantly greater than estimates for the most advanced continuous flow reactors used in the production of fine chemicals $\left(\mathrm{ca} .4 \times 10^{3} \mathrm{~kg} \mathrm{~m}^{-3} \mathrm{day}^{-1}\right)^{33}$ suggesting that TSE provides greater process intensification.

${ }^{1} \mathrm{H}$ NMR spectroscopy confirmed complete conversion to the $E$-isomer of $\mathbf{1}$ by comparison to literature data, ${ }^{34,35}$ with the $\mathrm{NH}$ and $\mathrm{CH}^{\mathrm{A}, \mathrm{p}}=\mathrm{N}$ protons resonating at 12.17 and 8.56 ppm respectively (Figure S1). The progress of the reaction was also monitored in solution by ${ }^{1} \mathrm{H}$ NMR spectroscopy in $d^{6}$ DMSO to ensure that the reaction did not proceed during the time scale of the solution NMR spectroscopy experiment. In particular, upon mixing $p$-nitrobenzaldehyde and benzhydrazide $(1: 2 \mathrm{~mol}$. eq $)$ in $d^{6}$-DMSO, the condensation reaction proceeded slowly in solution, with only $7 \%$ of $E-N$ acylhydrazone $\mathbf{1}$ formed after $90 \mathrm{~min}$ at room temperature, and with no-detectable isomerization byproduct. Therefore, we can conclude that $\mathbf{1}$ was formed by TSE, as determined by quantifying the conversion of starting material to product.

Although in the formation of $\mathbf{1}$ the reaction proceeded very slowly in the ${ }^{1} \mathrm{H}$ NMR spectroscopy solvent, there are several cases of related reactions, including some described below, that proceeded significantly within the time frame of a ${ }^{1} \mathrm{H}$ NMR spectroscopy experiment $(<2 \mathrm{~min})$. As a result, alternative methods of qualitative and quantitative analyses on the solidstate products were needed, such as ATR-IR spectroscopy.

An experiment was initially carried out to determine how fast a solid-state reaction would occur if the reagents were simply brought into contact with each other without the continued mixing that would occur under TSE. This would indicate whether, or not, a reaction could proceed in the solid state after the extrusion process (and before analysis could be conducted). A stoichiometric mixture of reactants was placed on an ATR-IR plate, and a constant pressure (i.e., force gauge) was applied to the powder continuously for over $90 \mathrm{~min}$ to bring it into good contact with the ATR crystal and ensure well-resolved IR spectra.

The carbonyl stretches for each reactant $\mathrm{CH}^{\mathrm{A}, \mathrm{r}}=\mathrm{O}(1702$ $\left.\mathrm{cm}^{-1}\right)$ and $\mathrm{PhC}=\mathrm{ONHNH}_{2}\left(1659 \mathrm{~cm}^{-1}\right)$ were monitored, and no reaction was detected (Figures S2 and S3). Thus, it follows that greater mechanical stress or mixing is needed to promote the reaction to a measurable extent. The reaction proceeded well when conducted by ball milling at $30 \mathrm{~Hz} .{ }^{1} \mathrm{H}$ NMR spectra showed that only $6 \%$ of residual aldehyde was present after $30 \mathrm{~min}$, with full conversion of the reagents occurring after $1 \mathrm{~h}$ with no evidence of $E$ to $Z$ isomerization of the newly formed $N$-acylhydrazone bond. Aging a mixture of solid reactants for 15 months confirmed further that the reaction did not proceed in the solid state even during this long time, as confirmed by ${ }^{1} \mathrm{H}$ NMR spectroscopy. In all cases, the conversions were determined by comparing the ${ }^{1} \mathrm{H}$ NMR signal of the $\mathrm{CH}^{\mathrm{A}, \mathrm{r}}=\mathrm{O}$ proton of $p$-nitrobenzaldehyde (at $10.16 \mathrm{ppm}$ ) to that of the corresponding $\mathrm{CH}^{\mathrm{A}, \mathrm{p}}=\mathrm{N}$ proton (at $8.56 \mathrm{ppm})^{34,35}$ of $(E)-N^{\prime}$-(4-nitrobenzylidene)benzohydrazide 1 (Scheme 2).

In addition, to further ensure that the reagents were fully converted by TSE, ${ }^{13} \mathrm{C}$ solid-state NMR spectroscopy was carried out on the extrudate (Figure 2). This confirmed that 
Scheme 3. Hydantoin-Based N-Acylhydrazones: Preparation of APIs 3 and 4 by TSE

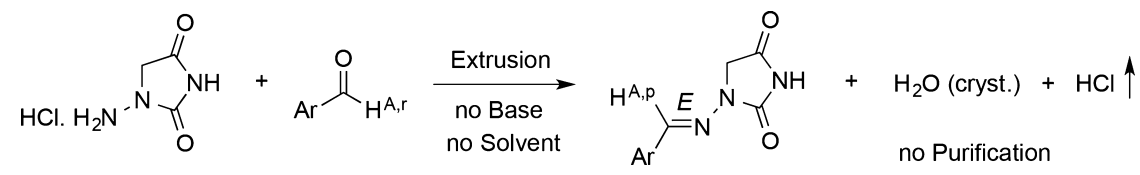<smiles>O=C1CN(/N=C(\O)c2ccc(-c3ccc([N+](=O)[O-])cc3)o2)C(=O)N1</smiles>

${ }^{a} \mathrm{H}^{\mathrm{A}, \mathrm{r}}$ and $\mathrm{H}^{\mathrm{A}, \mathrm{P}}$ indicate, respectively, the aldehyde proton in the reactant and the $N$-acylhydrazone proton in the product 3.

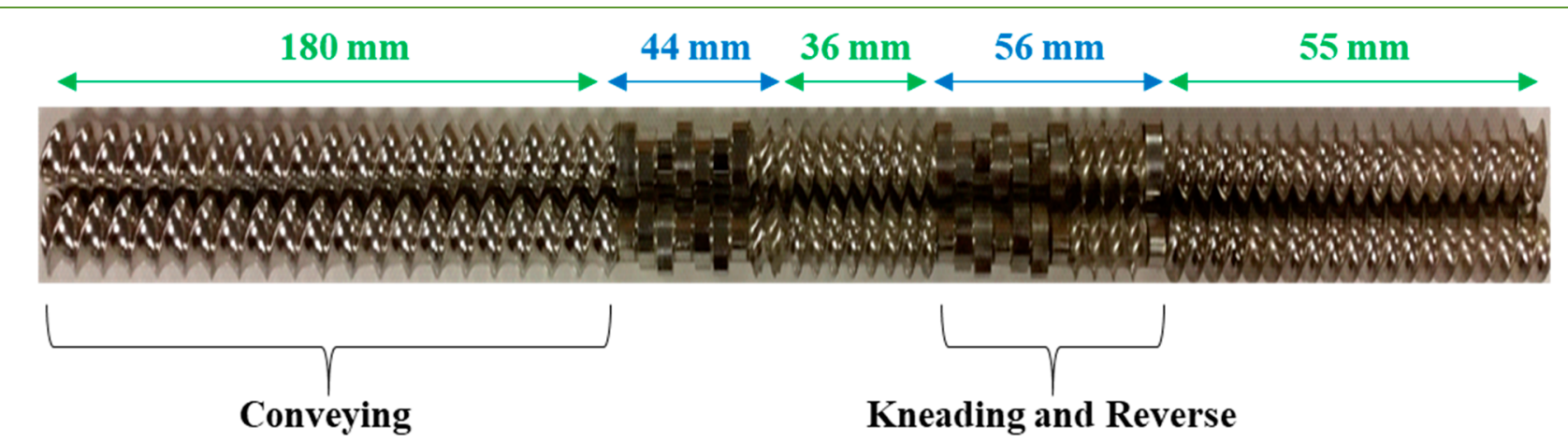

Figure 3. Reverse screw configuration employed in the extrusion of compounds 3 and 4.

(E)-N'-(4-nitrobenzylidene)benzohydrazide 1 was formed selectively and quantitatively. In particular, the $\mathrm{CH}^{\mathrm{A}, \mathrm{r}}=\mathrm{O}$ carbon signal of $p$-nitrobenzaldehyde (at $190.5 \mathrm{ppm}$ ) was not present in the ${ }^{13} \mathrm{C}$ solid-state NMR spectrum of 1 , while a new peak indicated the presence of the $\mathrm{N}$-acylhydrazone bond $\mathrm{CH}^{\mathrm{A}, \mathrm{p}}=\mathrm{N}$ carbon (at $166.5 \mathrm{ppm}$ ), assigned on the basis of previous studies. $^{34,35}$

It follows that both ATR-IR and ${ }^{13} \mathrm{C}$ solid state $\mathrm{NMR}$ spectroscopies allowed for the extrusion products to be analyzed without sample preparation that could promote the reaction, e.g., dissolution into a deuterated solvent or pressing into a $\mathrm{KBr}$ pellet. Therefore, these were considered reliable methods to monitor the progress of the extrusion reactions.

The reaction of $p$-nitrobenzaldehyde with phenyl acetic hydrazide to give $N$-acylhydrazone 2 was then investigated. ${ }^{1} \mathrm{H}$ NMR spectroscopy indicated that full conversion occurred at $150{ }^{\circ} \mathrm{C}$ and a screw speed of $55 \mathrm{rpm}$ (Table S2a). A STY of 52 $\times 10^{3} \mathrm{~kg} \mathrm{~m}^{-1} \mathrm{day}^{-1}$ was calculated. This value is similar to that obtained for the preparation of 1 . However, ${ }^{1} \mathrm{H}$ NMR spectroscopy showed that the reaction was not stereoselective, with an $E / Z$ ratio of $60 / 40$. The $E / Z$ ratio was attributed on the basis of previously reported studies, ${ }^{36}$ by comparing the ${ }^{1} \mathrm{H}$ NMR $\mathrm{CH}_{2}$ signal of $2-\mathrm{Z}$ (4.02 ppm) to the corresponding protons of $2-E(3.59 \mathrm{ppm})$. Variations of screw speed and extrusion temperature did not result in any stereoselectivity enhancement (Table S2a). It is worth noting that the $Z$-isomer is the major product by extrusion, while by ball milling the $E$ isomer is formed exclusively. This may be due to the combination of shearing forces and the high temperature employed in the extruder.

Furthermore, an analytically pure sample of $E-N$-acylhydrazone 2 , prepared by ball milling, was analyzed by ${ }^{1} \mathrm{H}$ NMR spectroscopy to investigate the stability of the $\mathrm{H}^{\mathrm{A}, \mathrm{p}} \mathrm{C}=\mathrm{N}$ bond in the E-configuration upon heating for a total of $2 \mathrm{~h}$ at $25{ }^{\circ} \mathrm{C}$ increments from room temperature to $150{ }^{\circ} \mathrm{C} .{ }^{37} \mathrm{No}$ conversion to the $Z$-isomer was observed. In addition, compound 2 showed no isomerization from $E$ to $Z$ in the solid state after 1 year (Figure S5).

The analogous solvent-based synthesis reported in the literature was reported to require an acid dehydrating agent. ${ }^{34}$ However, the TSE syntheses of both $N$-acylhydrazones $\mathbf{1}$ and $\mathbf{2}$ were successful without this additive, thereby further reducing waste and removing the need for postsynthetic workup.

Comparing the effects of benzyl/aliphatic versus an aryl substituent, it was found that a lower temperature (room temperature) was required for the benzyl hydrazide. However, in the formation of $\mathbf{2}$, using phenylacetic hydrazide, a temperature of $150{ }^{\circ} \mathrm{C}$ was required. This suggests that the formation of $\mathbf{1}$ requires less energy. Furthermore, we considered whether $\mathbf{2}$ was forming in the extruder as a result of heat only or a combination of heat and mechanical energy.

Control experiments were conducted (Table S2b, c) ${ }^{38}$ that confirmed that heating alone was sufficient for the reaction to be initiated and proceed to completion. However, it must be noted that upon scale-up TSE is likely to be advantageous as it provides a means of intimately mixing the substrates as well as an even distribution of heat transfer.

As production of $\mathbf{1}$ and $\mathbf{2}$ was successful by TSE, we investigated nitrofurantoin (3) and dantrolene (4). In these cases, the hydrazide group constitutes part of a heterocyclic ring, and therefore, the reactivity and optimization were expected to differ from those for $\mathbf{1}$ and $\mathbf{2}$.

The syntheses of nitrofurantoin $\mathbf{3}$ and dantrolene $\mathbf{4}$ were investigated starting from 1-aminohydantoin hydrochloride reacting with 5-nitro-2-furaldehyde or 5-(4-nitrophenyl)furfural, respectively ${ }^{31}$ (Scheme 3 ). 


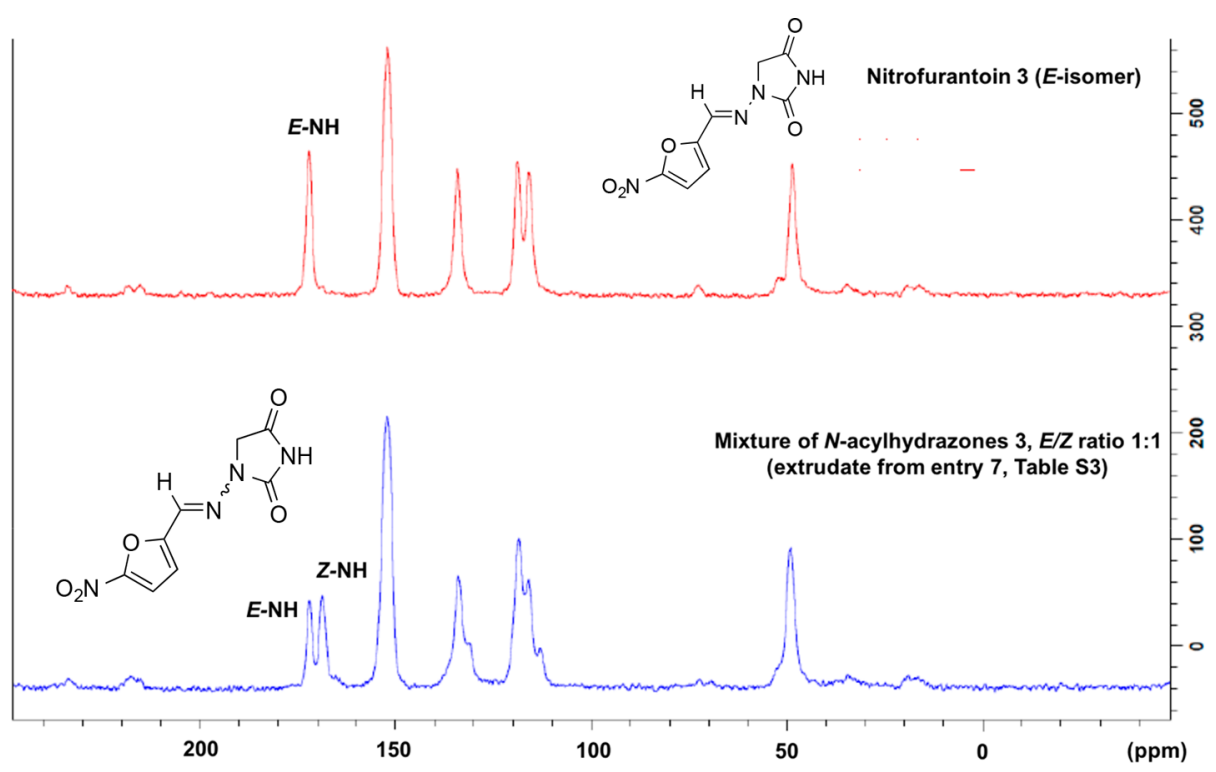

Figure 4. ${ }^{13} \mathrm{C}$ solid-state NMR spectra of extrudates: nitrofurantoin 3 (E-isomer from entry 1, Table S3, red pattern) vs $N$-acylhydrazones 3 (1:1 mixture of $E$ - and $Z$-isomers from entry 7 , Table $S 3$, blue pattern).
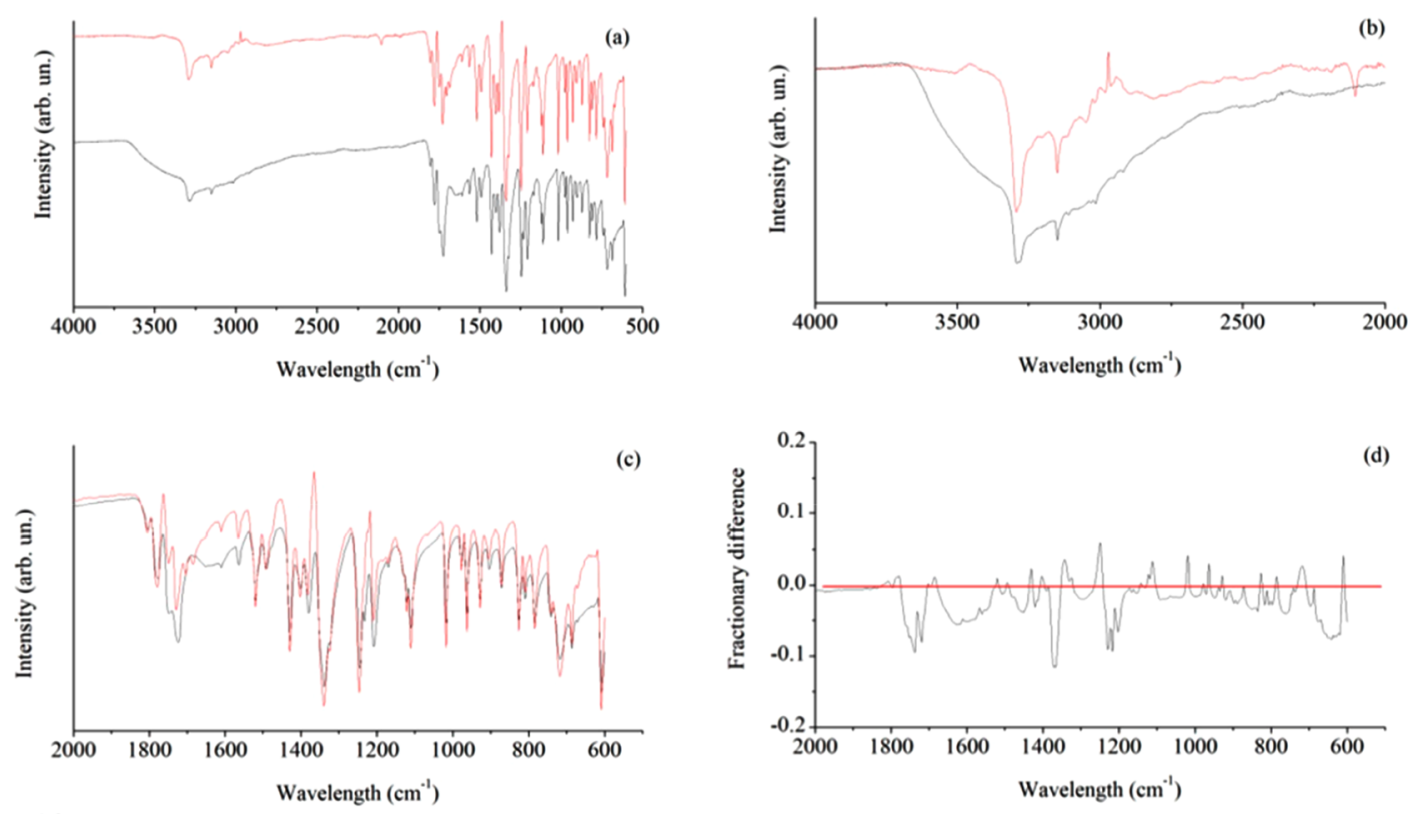

Figure 5. (a) Overlapping of FT-IR spectra of nitrofurantoin 3 prepared by ball milling (red pattern) and by extrusion (black pattern). (b) Nonfingerprint and (c) fingerprint regions. (d) Fractional difference within the fingerprint region between the FT-IR spectra of nitrofurantoin 3 prepared by ball milling and by TSE. Horizontal red line indicates zero discrepancy.

As previously demonstrated, the mechanochemical preparation of hydantoin avoids the need for a base, which is typically used to generate the nucleophilic amine in solution. ${ }^{31,39,40}$ Moreover, the presence of water and $\mathrm{HCl}$ generated during the synthesis do not cause hydrolysis of the newly formed acidlabile hydrazone bond. This is in agreement with previous findings in the literature, ${ }^{40}$ suggesting that the water formed during the condensation reaction may be present as "crystallization" water. ${ }^{31,41}$ This holds for both ball milling conditions (a closed system, with gaseous $\mathrm{HCl}$ confined to the jar) and extrusion conditions (an open system, from which the gas can escape). In cases where a significant amount of $\mathrm{HCl}$ is produced, the extruder is equipped with gas vents along the length of the barrel, in which the gas leaves through an airtight connection and can be transported to a basic aqueous solution for neutralization. There is also potential for valorization of this $\mathrm{HCl}$ byproduct. Scaling up the TSE process, producing greater quantities of $\mathrm{HCl}$ will not have an impact on the methodology employed to neutralize or reuse the byproduct; everything will just be scaled accordingly. This is already common in the polymer industry.

Preliminary experiments indicated that for the syntheses of 3 and 4, an alternative screw configuration was required, with reverse screw segments following each kneading section (Figure 3). These sections retard the flow of material through the barrel, thereby increasing the time that the material spends in the kneading sections and so providing greater mixing. As a result, the residence time increased $c a .40 \mathrm{~min}$. 

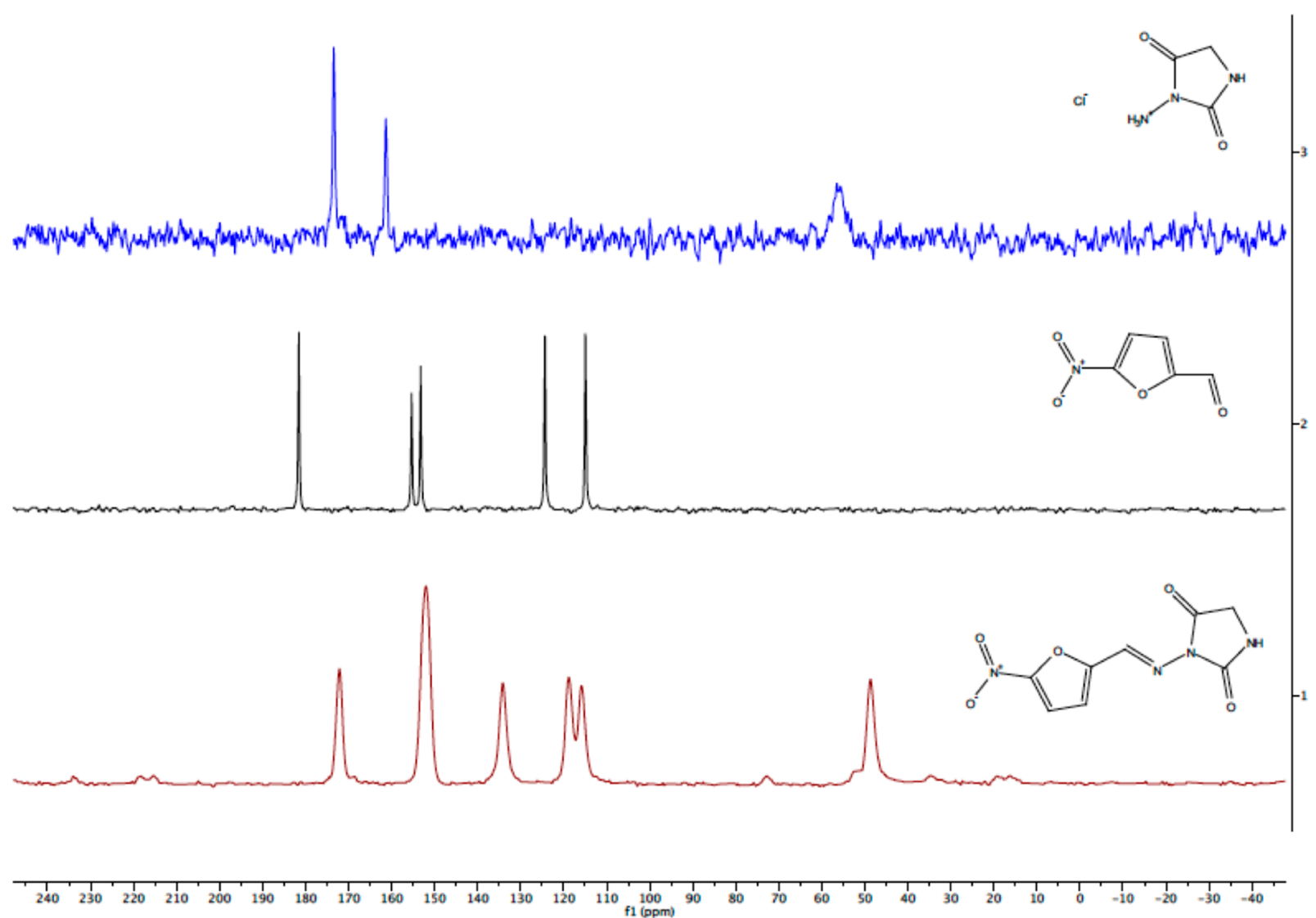

Figure $6 .{ }^{13} \mathrm{C}$ solid-state NMR spectra of reactants 1-aminohydantoin hydrochloride (blue pattern) and 5-nitro-2-furaldehyde (black pattern) vs nitrofurantoin 3 prepared by extrusion (red pattern).

To successfully prepare compound 3 (as confirmed by ATRIR and ${ }^{13} \mathrm{C}$ solid-state NMR spectroscopies, Figures 4 and 5), a screw speed of $30 \mathrm{rpm}$ at room temperature was required (Tables S3 and S4), leading exclusively to the $E$-isomer ${ }^{31}$ with an STY of $6.8 \times 10^{3} \mathrm{~kg} \mathrm{~m}^{-3} \mathrm{day}^{-1}$. The extrudate was a deep yellow powder (Table S3). It is important to emphasize here that control experiments (Figures S8-S10 and S12) showed that the solid reagents do not react when simply placed in contact with each other. Indeed, a solid mixture was monitored over $90 \mathrm{~min}$, and the reaction was not initiated, which confirms that the mechanical effects of the extruder are required for the reaction to occur.

As the crystal form of an API is important, powder X-ray diffraction (PXRD) was used to assess the crystallinity. The PXRD pattern of 3 showed it was largely amorphous, with only three clear diffraction peaks being observed (Figure S11). This was also seen from the reaction carried out in the SPEX mill. ${ }^{31}$ Therefore, the potential for TSE and ball milling to provide amorphous products directly can be regarded as a further advantage in the preparation of APIs since amorphous forms can exhibit enhanced bioavailability and drug dissolution rates. $^{42}$

Temperature and solvents have marked effects on stereoselectivity. Exploratory experiments show that, at higher temperatures, the extrudate obtained was a 50:50 mixture of $E$ - and $Z$-isomers. When acetonitrile was added to the reactants to provide liquid assisted grinding (LAG), the ratio increased to 70:30 in favor of the E-isomer (Table $S 3$ and Figure 4).

Figure 5 compares the FT-IR spectrum of 3 prepared by TSE with the product prepared by ball milling. ${ }^{31}$ Overall, there is good agreement between the spectra. Differences are between 3500 and $2800 \mathrm{~cm}^{-1}$ (which can be ascribed to different water contents) and around $1600 \mathrm{~cm}^{-1}$ (potentially related to different stretching $\mathrm{C}=\mathrm{C}$ stretching modes resulting from crystalline versus amorphous packing). Within the fingerprint region, we also evaluated the small differences between the FT-IR spectra of nitrofurantoin 3 prepared by ball milling and by TSE. Specifically, we subtracted the intensity of the FT-IR spectrum of nitrofurantoin obtained by ball milling from that of nitrofurantoin obtained by TSE and divided the result by the intensity of the spectrum of nitrofurantoin obtained by TSE (Figure 5d). The maximum fractional difference is $10 \%$. However, this is randomly distributed across the fingerprint region and involves both sharp, clearly overlapping peaks and the region around 1600 and 600 $\mathrm{cm}^{-1}$, where discrepancies seems more evident at a first sight. This suggests that statistical fluctuations in the preparation of samples and potentially the presence of very small amounts of impurities can possibly explain any observed differences.

The comparison of the ${ }^{13} \mathrm{C}$ solid-state NMR spectra of reagents and extrudate clearly indicates that the $\mathrm{CH}^{\mathrm{A}, \mathrm{r}}=\mathrm{O}$ carbon signal of 5-nitro-2-furaldehyde (at $175.5 \mathrm{ppm}$ ) was not present in the ${ }^{13} \mathrm{C}$ solid-state NMR spectrum of 3 . Indeed, a new peak due to the $N$-acylhydrazone $\mathrm{CH}^{\mathrm{A}, \mathrm{P}}=\mathrm{N}$ carbon (at $168.7 \mathrm{ppm}$ ) was present while the chemical shift of the $\mathrm{CH}_{2}$ group moved from $55.9 \mathrm{ppm}$ for 1-aminohydantoin hydrochloride to $49.1 \mathrm{ppm}$, consistent with the desired product ${ }^{31}$ (Figure 6).

Concerning the formation of 4 (dantrolene), ATR-IR spectroscopy indicated that high conversions were achieved. 


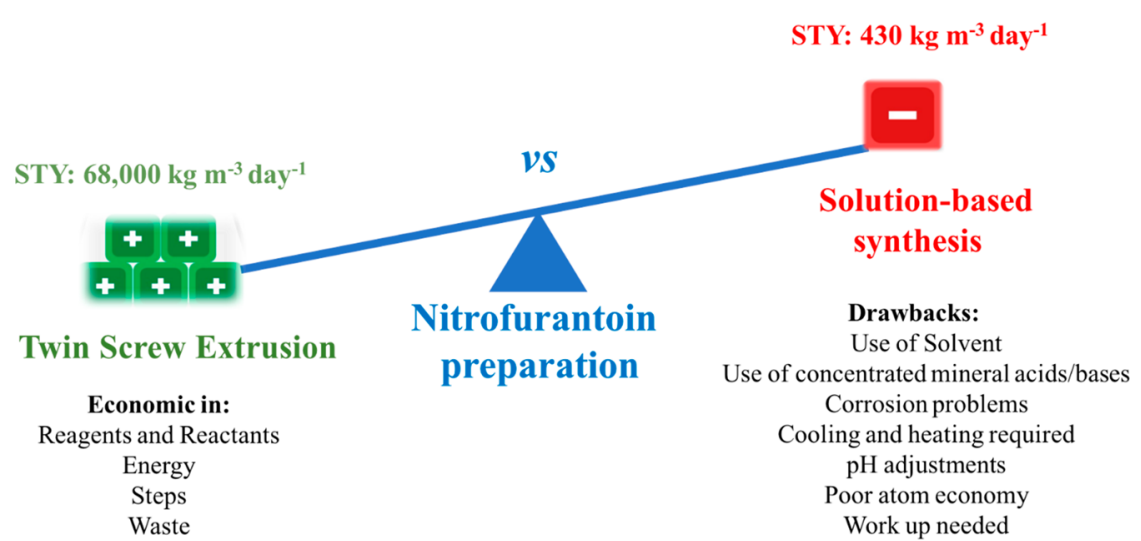

Figure 7. Advantages of TSE vs solution-based procedures. Preparation of nitrofurantoin 3 is given as an example.

However, some starting material still remained (Tables S6 and S7 and Figure S13). It is also worth noting that upon conversion to $\mathbf{4}$ in some cases only one isomer was observed, namely, the E-isomer ${ }^{31}$ (Table S7, entry D150). Therefore, while TSE clearly shows great promise for the solvent-free synthesis of dantrolene, the process requires further mechanistic study to allow the reaction to reach completion under solvent-free conditions, perhaps requiring a mild base.

\section{CONCLUSIONS}

In conclusion, TSE was applied to the preparation of a series of $\mathrm{N}$-acylhydrazones on a $25 \mathrm{~g}$ scale in the absence of solvent. Two examples of currently employed APIs have been investigated, namely, nitrofurantoin and dantrolene. TSE resulted in the successful synthesis of nitrofurantoin with very high conversions and stereoselectivities. The work demonstrates the potential of TSE for the efficient manufacture of APIs, with additional advantages compared to solution-based procedures (Figure 7).

Furthermore, extruders are designed to be "self-wiping", and as a result, there is only a very small amount of residual product left on the barrel and screw surfaces at the end of each process. In fact, there is less than $1 \mathrm{~g}$ of material typically lost via TSE synthesis.

\section{ASSOCIATED CONTENT}

\section{SI Supporting Information}

The Supporting Information is available free of charge at https://pubs.acs.org/doi/10.1021/acssuschemeng.0c03816.

Experimental details, PXRD analysis, FT-IR spectra, and solid state ${ }^{13} \mathrm{C}$ NMR spectra (PDF)

\section{AUTHOR INFORMATION}

\section{Corresponding Authors}

Evelina Colacino - ICGM, Univ Montpellier, CNRS, ENSCM, Montpellier, France; 이이.orido000-0002-1179-4913; Email: evelina.colacino@umontpellier.fr

Deborah E. Crawford - School of Chemistry and Chemical Engineering, Queen's University Belfast, BT9 5AG Northern Ireland, United Kingdom; School of Chemistry and Biosciences, University of Bradford, BD7 1DP Bradford, United Kingdom; ○ orcid.org/0000-0003-2579-7987; Email: D.Crawford@ bradford.ac.uk
Authors

Andrea Porcheddu - Dipartimento di Scienze Chimiche e Geologiche, Università degli Studi di Cagliari, Cittadella Universitaria, 09042 Monserrato, Ca, Italy; ㅈorcid.org/ 0000-0001-7367-1102

Aaron S. McCalmont - School of Chemistry and Chemical Engineering, Queen's University Belfast, BT9 5AG Northern Ireland, United Kingdom

Francesco Delogu - Dipartimento di Ingegneria Meccanica, Chimica e dei Materiali, Università degli Studi di Cagliari, 09123 Cagliari, Italy

Stuart L. James - School of Chemistry and Chemical Engineering, Queen's University Belfast, BT9 5AG Northern Ireland, United Kingdom

Complete contact information is available at:

https://pubs.acs.org/10.1021/acssuschemeng.0c03816

\section{Notes}

The authors declare no competing financial interest.

\section{ACKNOWLEDGMENTS}

E.C. is grateful to S.J. for mobility grant. This article is based upon work from COST Action CA18112, ${ }^{43-45}$ supported by COST (European Cooperation in Science and Technology). ${ }^{46}$ A.P. is grateful to MIUR for PRIN 2017, $\mathrm{n}^{\circ}$ 2017B7MMJ5_001, "MultIFunctional poLymer cOmposites based on groWn matERials (MI-FLOWER)”. E.C. acknowledges Mme Pascale Guiffrey (Institut Charles Gerhardt de Montpellier, ICGM, UMR 5253, France) for the technical support on FT-IR (ATR) analyses.

\section{REFERENCES}

(1) Gomollón-Bel, F. Ten Chemical Innovations That Will Change Our World. Chem. Int. 2019, 41, 12-17.

(2) James, S. L.; Adams, C. J.; Bolm, C.; Braga, D.; Collier, P.; Friščćc, T.; Grepioni, F.; Harris, K. D. M.; Hyett, G.; Jones, W.; Krebs, A.; Mack, J.; Maini, L.; Orpen, A. G.; Parkin, I. P.; Shearouse, W. C.; Steed, J. W.; Waddell, D. C. Mechanochemistry: opportunities for new and cleaner synthesis. Chem. Soc. Rev. 2012, 41, 413-447.

(3) Friščić, T.; Mottillo, C.; Titi, H. M. Mechanochemistry for Synthesis. Angew. Chem., Int. Ed. 2020, 59, 1018-1029.

(4) Tan, D.; Garcia, F. Main group mechanochemistry: from curiosity to established protocols. Chem. Soc. Rev. 2019, 48, 22742292.

(5) Porcheddu, A.; Colacino, E.; De Luca, L.; Delogu, F. MetalMediated and Metal-Catalyzed Reactions Under Mechanochemical Conditions. ACS Catal. 2020, 10, 8344-8394. 
(6) Bolm, C.; Hernandez, J. From Synthesis of Amino Acids and Peptides to Enzymatic Catalysis: A Bottom-Up Approach in Mechanochemistry. ChemSusChem 2018, 11, 1410-1420.

(7) Braga, D.; Maini, L.; Grepioni, F. Mechanochemical preparation of co-crystals. Chem. Soc. Rev. 2013, 42, 7638-7648.

(8) Lazuen-Garay, A.; Pichon, A.; James, S. L. Solvent-free synthesis of metal complexes. Chem. Soc. Rev. 2007, 36, 846-855.

(9) Cabras, V.; Pilloni, M.; Scano, A.; Lai, R.; Aragoni, M. C.; Coles, S. J.; Ennas, G. Mechanochemical Reactivity of Square-Planar Nickel Complexes and Pyridyl-Based Spacers for the Solid-State Preparation of Coordination Polymers: The Case of Nickel Diethyldithiophosphate and 4,4'-Bipyridine. Eur. J. Inorg. Chem. 2017, 2017, 19081914.

(10) Zhu, S. E.; Li, F.; Wang, G.-W. Mechanochemistry of fullerenes and related materials. Chem. Soc. Rev. 2013, 42, 7535-7570.

(11) Balaz, P.; Achimovicova, M.; Balaz, M.; Billik, P.; CherkezovaZheleva, Z.; Criado, J. M.; Delogu, F.; Dutkova, E.; Gaffet, E.; Gotor, F. J.; Kumar, R.; Mitov, I.; Rojac, T.; Senna, M.; Streletskii, A.; Wieczorek-Ciurowa, K. Hallmarks of mechanochemistry: from nanoparticles to technology. Chem. Soc. Rev. 2013, 42, 7571-7637.

(12) Munoz-Batista, M.; Rodriguez-Padron, D.; Puente-Santiago, A. R.; Luque, R. Mechanochemistry: Toward Sustainable Design of Advanced Nanomaterials for Electrochemical Energy Storage and Catalytic Applications. ACS Sustainable Chem. Eng. 2018, 6, 95309544.

(13) Hasa, D.; Jones, W. Screening for new pharmaceutical solid forms using mechanochemistry: a practical guide. Adv. Drug Delivery Rev. 2017, 117, 147-161.

(14) Tan, D.; Loots, L.; Friscic, T. Towards medicinal mechanochemistry: evolution of milling from pharmaceutical solid form screening to the synthesis of active pharmaceutical ingredients (APIs). Chem. Commun. 2016, 52, 7760-7781.

(15) Quaresma, S.; André, V.; Fernandes, A.; Duarte, M. T. Mechanochemistry - A green synthetic methodology leading to metallodrugs, metallopharmaceuticals and bio-inspired metal-organic frameworks. Inorg. Chim. Acta 2017, 455, 309-318.

(16) Pérez-Venegas, M.; Juaristi, E. Mechanochemical and Mechanoenzymatic Synthesis of Pharmacologically Active Compounds: A Green Perspective. ACS Sustainable Chem. Eng. 2020, 8, $8881-8893$

(17) Colacino, E.; Porcheddu, A.; Charnay, C.; Delogu, F. From enabling technologies to medicinal mechanochemistry: an ecofriendly access to hydantoin-based active pharmaceutical ingredients. Reac. Chem. Eng. 2019, 4, 1179-1188.

(18) Cao, Q.; Crawford, D. E.; Shi, C.; James, S. L. Greener Dye Synthesis: Continuous, Solvent-Free Synthesis of Commodity Perylene Diimides by Twin-Screw Extrusion. Angew. Chem., Int. Ed. 2020, 59, 4478-4483.

(19) Crawford, D.; Miskimmin, C. K. G.; Cahir, J.; James, S. L. Continuous Multi-Step Synthesis By Extrusion - Telescoping Solvent-Free Reactions For Greater Efficiency. Chem. Commun. 2017, 53, 13067-13070.

(20) Crawford, D. E.; Miskimmin, C. K. G.; Albadarin, A. B.; Walker, G.; James, S. L. Organic Synthesis By Twin Screw Extrusion (TSE): Continuous, Scalable and Solvent-Free. Green Chem. 2017, 19, $1507-1518$

(21) Crawford, D.; Casaban, J.; Haydon, R.; Giri, N.; McNally, T.; James, S. L. Synthesis By Extrusion: Continuous, Large-Scale Preparation Of MOFs Using Little Or No Solvent. Chem. Sci. 2015, $6,1645-1649$.

(22) Karadeniz, B.; Howarth, A. J.; Stolar, T.; Islamoglu, T.; Dejanović, I.; Tireli, M.; Wasson, M. C.; Moon, S.-Y.; Farha, O. K.; Friščić, T.; Užarević, K. Benign by Design: Green and Scalable Synthesis of Zirconium UiO-Metal-Organic Frameworks by WaterAssisted Mechanochemistry. ACS Sustainable Chem. Eng. 2018, 6, 15841-15849.

(23) Ardila-Fierro, K. J.; Crawford, D. E.; Koerner, A.; James, S. L.; Bolm, C.; Hernandez, J. G. Papain-Catalysed Mechanochemical Synthesis of Oligopeptides By Milling And Twin-Screw Extrusion:
Application in the Juliá-Colonna Enantioselective Epoxidation. Green Chem. 2018, 20, 1262-1269.

(24) Yeboue, Y.; Gallard, B.; Le Moigne, N.; Jean, M.; Lamaty, F.; Martinez, J.; Métro, T.-X. Peptide Couplings By Reactive Extrusion: Solid-Tolerant And Free From Carcinogenic, Mutagenic and Reprotoxic Chemicals. ACS Sustainable Chem. Eng. 2018, 6, 16001-16004.

(25) Krause, T.; Gerbershagen, M. U.; Fiege, M.; Weisshorn, R.; Wappler, F. Dantrolene - A Review Of Its Pharmacology, Therapeutic Use and New Developments. Anaesthesia 2004, 59, 364-373.

(26) Guay, D. R. An Update On The Role Of Nitrofurans In The Management Of Urinary Tract Infections. Drugs 2001, 61, 353-364.

(27) Li, X.; Zhang, F. Method For Preparing And Refining Nitrofurantoin. CN Patent 101450941A20071130, 2009.

(28) Malkawi, A. Co-Solvent Compositions and Methods For Improved Delivery Of Dantrolene Therapeutic Agents. U.S. Patent 20090093531 A1, 2009.

(29) Portelli, M. Process For The Manufacture of N-(5-Nitro-2Furfurylidene)-1-Amino-Hydantoin. U.S. Patent 3427306, 1969.

(30) Stewert, D. C.; Snyder, J. H. R. 1-(5-Substituted) Furfurylideneamino Hydantoins and Imidazolidinones. U.S. Patent 3415821 A, 1968.

(31) Colacino, E.; Porcheddu, A.; Halasz, I.; Charnay, C.; Delogu, F.; Guerra, R.; Fullenwarth, J. Mechanochemistry for "no solvent, no base" preparation of hydantoin-based active pharmaceutical ingredients: nitrofurantoin and dantrolene. Green Chem. 2018, 20, 29732977.

(32) Konnert, L.; Lamaty, F.; Martinez, J.; Colacino, E. Recent Advances in the Synthesis of Hydantoins: The State of the Art of a Valuable Scaffold. Chem. Rev. 2017, 117, 13757-13809.

(33) Baumann, M.; Moody, T. S.; Smyth, M.; Wharry, S. A Perspective on Continuous Flow Chemistry in the Pharmaceutical Industry. Org. Process Res. Dev. 2020, na DOI: 10.1021/acs.oprd.9b00524.

(34) Morales, S.; Aceña, J. L.; García Ruano, J. L.; Cid, M. B. Sustainable Synthesis of Oximes, Hydrazones and Thiosemicarbazones Under Mild Organocatalyzed Reaction Conditions. J. Org. Chem. 2016, 81, 10016-10022.

(35) Tumkevicius, S.; Mekuskiene, G.; Gefenas, V.; Vainilavicius, P. Substituent Effect on Proton Chemical Shifts of Amide and Azomethine Groups of Arylidenehydrazides of 5-Substituted 2Pyrimidine-Carboxylic Acids and Their Aromatic Analogs. Chemjia 2005, 16, 65-68.

(36) Oliveira, P. F. M.; Baron, M.; Chamayou, A.; Andre-Barres, C.; Guidetti, B.; Baltas, M. Solvent-Free Mechanochemical Route For Green Synthesis Of Pharmaceutically Attractive Phenol-Hydrazones. RSC Adv. 2014, 4, 56736-56742.

(37) Compound 2 was kept for $2 \mathrm{~h}$ at $25,75,100,125$ and $150{ }^{\circ} \mathrm{C}$. For each experiment under isothermal conditions, a new sample was used. Experiments were conducted in the NMR tube using $d_{6}$-DMSO as the solvent. First, the temperature of the oil bath was set each time at the desired value. Then, the NMR tube was immersed into the oil bath and left there for $2 \mathrm{~h}$. The NMR spectra were collected immediately after such time intervals.

(38) Ishibashi, F.; Nashima, T.; Nishino, J.; Kobayashi, I.; Ichihara, Y.; Kitagawa, Y.; Sasaki, S.; Yoshikawa, M.; Matsuoka, A.; Yamamoto, K. Geometrical Isomerism Of Phenylhydrazones Of $\alpha$-Keto Esters. II. p-Substituted Phenylhydrazones Of Ethyl Pyruvate And 2,4Dinitrophenylhydrazones Of Some $\alpha$-Keto Esters. Bull. Chem. Soc. Jpn. 1986, 59, 73-76.

(39) Konnert, L.; Gonnet, L.; Halasz, I.; Suppo, J.-S.; de Figueiredo, R. M.; Campagne, J.-M.; Lamaty, F.; Martinez, J.; Colacino, E. Mechanochemical Preparation of 3,5-Disubstituted Hydantoins from Dipeptides and Unsymmetrical Ureas of Amino Acid Derivatives. J. Org. Chem. 2016, 81, 9802-9809.

(40) Lanzillotto, M.; Konnert, L.; Lamaty, F.; Martinez, J.; Colacino, E. Mechanochemical 1,1'-Carbonyldiimidazole-Mediated Synthesis Of Carbamates. ACS Sustainable Chem. Eng. 2015, 3, 2882-2889. 
(41) Pienaar, E. W.; Caira, M. R.; Lötter, A. P. Polymorphs Of Nitrofurantoin. 2. Preparation And X-ray Crystal Structures Of Two Anhydrous Forms Of Nitrofurantoin. J. Crystallogr. Spectrosc. Res. 1993, 23, 785-790.

(42) Kanaujia, P.; Poovizhi, P.; Ng, W.K.; Tan, R.B.H. Amorphous Formulations For Dissolution And Bioavailability Enhancement Of Poorly Soluble APIs. Powder Technol. 2015, 285, 2-15.

(43) For more information on COST Action CA18112 "Mechanochemistry for Sustainable Industry” (MechSustInd), see http:// www.mechsustind.eu/ (accessed July 14, 2020).

(44) Baláž, M.; Vella-Zarb, L.; Hernandez, J.; Halasz, I.; Crawford, D. E.; Krupička, M.; André, V.; Niidu, A.; Garcia, F.; Maini, L.; Colacino, E. Mechanochemistry: A Disruptive Innovation for the Industry of the Future. Chemistry Today 2019, 37, 32-34.

(45) Hernández, J. G.; Halasz, I.; Crawford, D. E.; Krupička, M.; Baláž, M.; André, V.; Vella-Zarb, L.; Niidu, A.; García, F.; Maini, L.; Colacino, E. European Research In Focus: Mechanochemistry For Sustainable Industry (COST Action MechSustInd). Eur. J. Org. Chem. 2020, 2020, 8-9.

(46) For more information on COST Association, see http://www. cost.eu/ (accessed July 14, 2020). 